\title{
Teaching Factoring Quadratics Using the Generic Rectangle for Sophomore Students
}

\author{
Manuel Sandoval Martínez (Corresponding author) \\ Dept. of Petroleum Engineering
}

Carr. Fed. Malpaso-El Bellote, Km 171. Monte Adentro, Paraíso, Tabasco, México

Tel: 52-01-933-11-00-382_E-mail: manuelsandova1804@gmail.com

\author{
Maricela García Avalos \\ Dept. of Petroleum Engineering
}

Carr. Fed. Malpaso-El Bellote, Km 171. Monte Adentro, Paraíso, Tabasco, México

\author{
Gerardo E Sepúlveda Palacios \\ Dept. of Petroleum Engineering
}

Carr. Fed. Malpaso-El Bellote, Km 171. Monte Adentro, Paraíso, Tabasco, México

\begin{abstract}
Carmen del Pilar Suárez Rodríguez
Coordinación Académica Región Huasteca Sur, Universidad Autónoma de San Luis Potosí Km. 5 Carretera Tamazunchale-San Martin C.P. 79960 Tamazunchale, S.L.P., México E-mail: pilar.suarez@uaslp.mx
\end{abstract}

Received: December 19, 2016 Accepted: January 13, 2017 Published: January 23, 2017 doi:10.5296/ire.v5i1.10470 URL: http://dx.doi.org/10.5296/ire.v5i1.10470

\begin{abstract}
Results about a mathematical tool, called Generic Rectangle (GR), applied in a preparatory course in order to resolve algebraic problems such as multiplying binomials and factoring quadratics are shown. Such tool was used in the "introduction to engineering" subject at
\end{abstract}


Universidad Politécnica del Golfo de Mexico (UPGM); up to 2014, this subject's failure rate was very high (near 60\%) in which traditional teaching method was used. After some curricular changes, including GR tool adopted in class, several objectives such as failure rate decrease (60\% to $15 \%)$, notably motivation and enhancement increase (Likert's test), and development of logic-mathematics reasoning, among others, could be reached. Results in 2015 indicates that $84 \%$ of population solved properly the final exam using GR; but regarding to those who worked with traditional method, just $25 \%$ of population obtained satisfactory results (2014); it means that GR is a better tool than traditional teaching method. Likert's test results indicate that students developed a strong positive attitude when they work with GR, however attitude of students who used traditional teaching method were strong negative.

Keywords: Generic Rectangle, Multiplying Binomial, Factoring Quadratics, Mathematics Attitude

\section{Introduction}

Studies related to educational process show that one of the most controversial areas is math teaching. Nowadays, the concern grows since failure rates increase rather than decrease as in most of mathematic subjects of the petroleum-engineering bachelor in UPGM. Another cause of school failure in mathematics and of the growing apathy of students is related to the understanding of the teaching-learning processes that would facilitate the natural development of individuals as well as their comprehensive training. Researches on attitudes, underscore the importance in the selection, interpretation and processing of information, which operates at all stages of learning: attention, perception, coding, interpretation and processing. This explains why the consistent information with attitudes is easier to encode in long-term memory. Likewise, the inconsistent information is suppressed, censored or, otherwise, tended to be forgotten (Alvarez \& Ruiz Soler, 2010). Therefore, attitudes are considered a good predictor in assimilation of content, motivation and future use of knowledge, which ultimately can either impede or facilitate learning. According to Salazar et al. (2013), these indicators are one of the reasons why it is necessary to look for teaching-learning alternatives that enable a significant improvement in this area. Such alternatives should be based on the experience gained from the analysis of successes and failures in the educational task and, at the same time, they should bring about changes in the teaching and learning of mathematics and improve the formation of student personality.

For the particular case of algebra, one of such teaching-learning techniques is problem solving, where the main purpose is to exercise logical thinking among students. According to Shoenfield (2013), success in solving a problem depends, among other factors, on own strategies that each individual apply to solve the problem; learning algebra based on the discussion, analysis and troubleshooting has given favorable results at basic level (Rojas, 2009). However, reorientation of this activity by proposing new teaching aids in order to enrich the above and to advance in the understanding, analysis and assimilation of algebra, must continue. Therefore, in order to achieve the goals in the new didactic resources, must be taken into account: promoting constant teacher's update to help in the search of ways to 
support or provide developments in the student learning.

Another strategy to be mentioned is study of cases, where motivation and mathematical reasoning is promoted as well as the strengthening of the practice of teachers in this area. Boehrer and Linsky (1990) concluded that this alternative strategy promotes the development of cognitive skills; encourages mathematical reasoning so learners can achieve to solve applicable to real life problems; and motivates learning because of the use of material and teaching resources, which drives the development of mathematical skills.

According to Morales and Sepulveda (2009), geometric algebra is an alternative tool that can provide ideas to factorize some sort of polynomials that appear in the school context. Certainly, it is an educational option that should be explored, once the students are familiar with situations of addition and subtraction of areas, as it allows the viewing and manipulation of these elements and can contribute to a better understanding of algebraic factorization procedures. This idea arose several decades ago with the book Why Jhonny can't add? (Kline, 1973) in which a geometric tool for multiplying binomials, by means of adding areas of a rectangle is shown. Sharp (1995) mentions that most academic programs of algebra in middle and high schools require students to memorize procedures, to have isolated knowledge, among others, which makes them acquire low-level skills and a no-significant learning. It should be recognized algebra is a math language where groups of symbols have a specific meaning, tending to create difficulties in acquiring a recognizable meaning. Gatley (1991) showed that students in some schools in Vancouver learn concepts faster and recall procedures better when using a tool called algebra tiles, which is classified as a manipulative material and that has a positive influence on student performance (Sowell, 1989; Kurumeh, 2010). Heddens (1985) defines the manipulative material as an object of real life in which learners revolve around it in order to appropriate the mathematical concepts. Larbi (2011) found that the use of algebra tiles significantly improved student performance compared to a control group (using traditional teaching method), besides, he found no significant differences between men and women when using this tool.

\section{Framework}

On the other hand, the Universidad Politécnica del Golfo de México (UPGM) offers a preparatory course with the intention of improving the academic level of new students, mainly in areas such as physics and mathematics. During the years that the mentioned course have been taught, it has been seen a high failure rate (nearly 60\%) in the subject "Introduction to Engineering" in which algebraic, geometric and trigonometric issues are discussed. After an analysis of that subject's recorded grades in the school services department, we found that the biggest problem lies in the areas of algebra (mainly factorization) finding out that students have serious difficulties to learn the basic rules in this math area.

For the above, it was proposed to work with manipulatives tools (such as generic rectangle) for teaching algebra, so students could acquire logical reasoning skills, allowing them to efficiently solve algebraic problems contextualized in petroleum engineering (Sandoval et al., 20014). Algebra, is an essential tool for any area of science and, by nature, it has an abstract 
language. Particularly in petroleum engineering, these operations are necessary to:

- Analyze the motion of a fluid in a pipe

- Find the rheological model of a drilling fluid

- Compute the permeability of a medium, among others.

Therefore, some of the main objectives of this research are:

$\checkmark$ Improve learning factorization

$\checkmark$ Reduce the failure rate in introduction to engineering

$\checkmark$ Increase motivation and participation in class.

The strategy focused on the use of competency-based model, in which students should develop generic and specific skills (Tobon, 2010; Arriaga, 2011); we will also refer to teamwork strategies.

\section{Methodology}

In order to develop this research, a pre-test named Mathematics Attitudinal Questionnaire (Thornton, 2011) was applied to measure the level of motivation and perception of students towards mathematics. The instrument was split in three sections (A: attitude in general; B: attitude on group work; C: students' felt in math) but we use just A and B section. According to Thornton, students receive five points if they have a strong positive attitude, four points for positive attitude, three points for indifferent, two points for negative attitude and one point for strong negative attitude (more detail in Section5).

To measure the level of learning, activities in class (individual and group) on factoring quadratics using GR were analyzed; as well as the results of the final exam that students presented in this course. Then, we compared those results vs previous year (only the written evaluation). The teaching sequence has as a main tool, the use of a generic rectangle and, thus, the making of operations of binomial product and factoring polynomials of second degree with an emphasis in petroleum engineering applications. Collaborative work among students was proposed, for this reason teams of four students who discussed strategies that should be followed to solve a given problem were formed, all this during10 minutes; all members gave their opinion on the exercise to solve (it is vitally important that the instructor monitor the development of each activity to ensure that teams works together). Subsequently, a group discussion for five minutes was conducted for feedback and rethink new ideas.

At the end of the course, post-test (similar to MAQ) named Generic Rectangle Attitudinal Questionnaire (GRAQ, see Annex 1) was applied to make a comparison between their perception at the beginning and at the end of the course (just in 2015) and Thornton's condition for MAQ was followed. It means, GRAQ was split into only two section: attitude in general and attitude on group work. For more details, see Section 5.

Perceptions are measured in SP (strong positive), N (neutral), and SN (strong negative), in both pretest and posttest. The course lasted three weeks, covering $40 \mathrm{hrs}$. Students were, on average, 18.5 years old, recently graduated from high school level and the total population was 28 students. In this study, no gender distinction was made, because Santos (2006) notes 


\section{Macrothink}

in a recent research there were no significant differences between men and women in their math performance when working with manipulatives. Population in 2014 was very similar to 2015 , number of students was 30 and the average age was 19.2 years old.

\section{The generic Rectangle Rules}

\subsection{Procedure for Use the Generic Box}

Algebra tiles is a geometric tool based on the sum of areas for operations of multiplication, division and some polynomials factorization. You must create a set of tiles of three sizes namely: square of side $\mathrm{x}$, rectangle long $\mathrm{x}$ and base 1 , and square of side 1; this assembly is used to visually represent the terms of a polynomial (generic rectangle is a simplification of algebra tiles and is easy to move from one representation to another). In Figure 1, the algebra tiles and GR representation of the polynomial $x^{2}+5 x+8$ is shown.

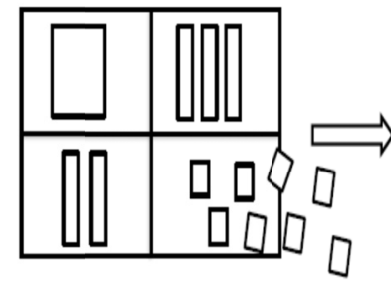

Algebra tiles

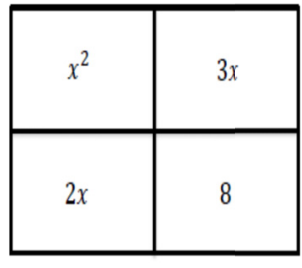

Generic rectangle

Figure 1. From algebra tile to generic rectangle

A little disadvantage that can be noticed in the algebra tiles is, when working with large coefficients polynomials it will involve a large number of unit squares, for example the polynomial $30 x^{2}+18 x-20$ requires to draw 30 frames of sides $x, 18$ rectangles of long $x$ and side 1 , and 20 small squares, which causes a very large time consumption.

Since 2015, it was proposed to work with GR for the primary topics of factorization, in the "introduction to engineering" subject at UPGM. This new tool consists in analyzing the binomial product using sums of areas of a rectangle whose sides are built using the binomials to multiply and thereby form four sub-areas (see Figure 2). Thus, the sum of all sub-areas allows to get the result of the product on an easier, clearer and more understandable way (Kline, 1973; Arriaga, 2011, Baldor, 2012; Ibañez, 2010).

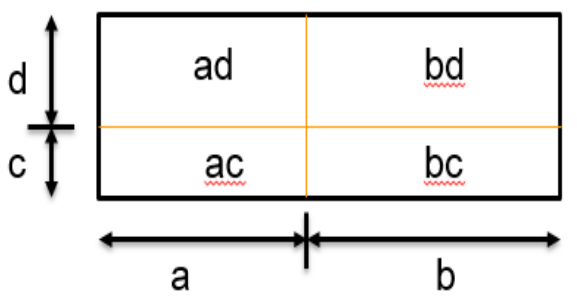

Figure 2. Binomial product with GR 


\section{Macrothink}

Can be used this idea to perform factorization, only that the procedure is a little different and have to follow some simple rules. For example, $y=a x^{2}+b x+c$ is a polynomial of the second degree. To factor it by the generic rectangle, should be followed the next steps.

Algorithm 1.1 Procedure for developing the generic rectangle.

1. Draw a rectangle and divide it into four parts.

2. Place the quadratic term $\left(\mathrm{ax}^{2}\right)$ in the lower left corner and the independent term (c) in the upper right corner.

3. Find two numbers $m$ and $n$ such that $m n=a c$ and $m \pm n=b$.

4. $\mathbf{m x}$ and $\mathbf{n x}$ terms are placed in the remaining corners, so that the algebraic sum of them match the linear term.

5. Find the common factor for both columns and rows. Thus, the sides of the rectangle are obtained (the values of the constants correspond to those of $m$ and $n$ ) and thus the result of the factorization is the area of the rectangle.

For example, to factoring $\mathrm{x}^{2}+7 \mathrm{x}-18$, we use Algorithm 1.1 to build the rectangle showed in Figure 3. Observe, in the first row, the common factor is -2 ; in the second row, it is $\mathrm{x}$. For the columns, they are $x$ and 9, respectively. So, the binomials are $(x-2)$ and $(x+9)$. As consequence: $\mathrm{x}^{2}+7 \mathrm{x}-18=(\mathrm{x}-2)(\mathrm{x}+9)$. As we can see, factorization is very easy.

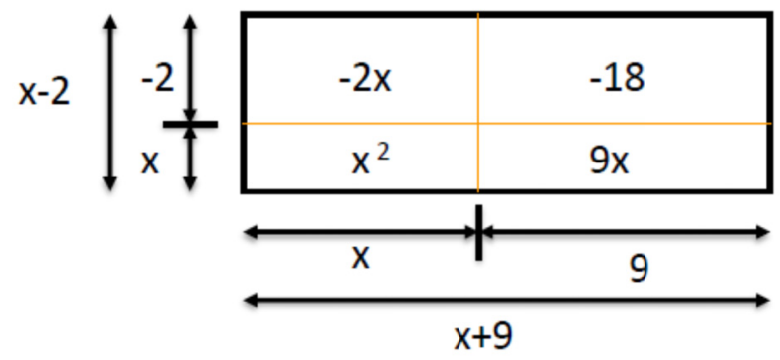

Figure 3. Procedure to factoring with GR

As second example, factoring $3 \mathrm{x}^{2}+7 \mathrm{x}-6$. We proceed according to Algorithm 1.1 (see Figure 4). In this case, the factorization is:

$$
3 x^{2}+7 x-6=(3 x-2)(x+3)
$$

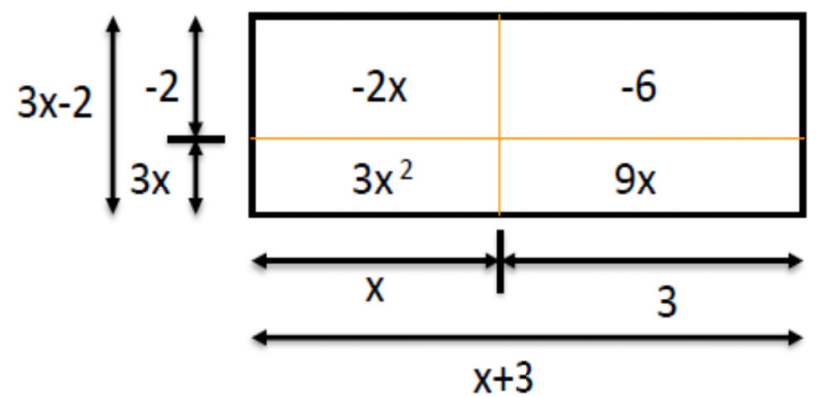

Figure 4. Generic rectangle for second example 
With this tool, students have the possibility to connect geometric representations with complex representation in a clearer and more understandable way. It is considered that this procedure will be useful for those students who have problems with factoring polynomials; in UPGM that kind of population is very high. An extra in this methodology was to introduce context problems, mainly focused on petroleum engineering to several areas like drilling fluids, PVT analysis, drilling cost, etc (Sandoval et al., 2014). This provoked a high interest in students for class. Some advantages of this tool are:

- Time consumption is low

- Abstraction is reduced

- Factorization rules are learned easier

A very important note is, we are not comparing algebra tiles with GR in this research. We are comparing GR with traditional teaching. In next Section, we show our result about that.

\section{Results}

\subsection{Academic Performance Comparison}

In this section, results of MAQ test and results of final exam taken by the students are shown; a comparative between the 2014 and 2015 courses was made (only for the final exam). In 2014 , students used traditional teaching method in order to solve the proposed problems (in 2015, they used the GR method). Table 1, shown results obtained in both years; it can be observed that the best results were achieved in 2015 , because $84 \%$ of the population applied correctly GR method in the final exam, solving correctly the proposed problems (only $16 \%$ failed). In 2014, students who applied the traditional teaching method in their final exam answered (correctly) less than $30 \%$ of problems, which represents a very low academic performance in this category. Here, it is necessary to make an observation: in 2014, instruction focused on solving textbook problems (Baldor, 2012); in 2015, instruction focused on competency-base model, principally on contextualized problems (Sandoval et al., 2014). On the other hand, in order to determine if there were significant differences between both teaching methods, a hypothesis test of two samples, taken from 2014 and 2015, was made.

Table 1. Comparison between 2014 and 2015 exams

\begin{tabular}{|c|c|c|c|c|}
\hline Year & Methodology & Population & Correct & Incorrect \\
\hline $\mathbf{2 0 1 4}$ & Traditional & 30 & $28 \%$ & $72 \%$ \\
\hline $\mathbf{2 0 1 5}$ & GR & 28 & $84 \%$ & $16 \%$ \\
\hline
\end{tabular}

The hypothesis to be tested is:

$\mathrm{H}_{0}$ : There are not significant differences between GR and traditional method for factoring learning.

$\mathrm{H}_{1}$ : There are significant differences between $\mathrm{GR}$ and traditional method for factoring learning. 
Using a level of significance of $5 \%$, and because the number of members of both populations is less than 30, we use t-student distribution with 56 degrees of freedom with a critical value $\mathrm{t}=1.671$; with these data, the standard error of the difference between two proportions using pooled estimates of both samples is $\sigma=0.1679$. The standardized difference between the two ratios is $t=3.5121$, from which can be seen that this value is outside the zone of acceptance and for that reason the null hypothesis is rejected, therefore we can infer that there are significant differences between both methods, and consequently GR produces better results than traditional method. It is worth mentioning that the failure rate decreased (from 60 to $15 \%)$ in 2015, fulfilling the first and second mains goals of this research.

\subsection{GR Method's Acceptance Level}

Another posed goal was to increase the level of participation and motivation of students who enrolled in introduction to engineering in 2015. Following the Thornton ideas (1995), a Likert's survey was applied (scale of 1 to 5) at the beginning of the course with the intention to know the (positive or negative) changes that could have had the students in their attitude toward mathematics. The survey was split into two sections: I) individual attitudes (personal), II) collaborative attitudes (teamwork).

As an example, a sentence could be:

\section{Math is dull}

$\begin{array}{llllll}\begin{array}{l}\text { A. strongly } \\ \text { agree }\end{array} & \text { B. agree } & \text { C. undecide } & \text { D. disagree } & \begin{array}{l}\text { E. strongly } \\ \text { disagree }\end{array}\end{array}$

\section{I enjoy working in groups to study and work on mathematics}
A. strongly
B. agree
C. undecide
D. disagree
agree
E. strongly
disagree

The scale used for this survey was as follows: a value of 5 is given to strongly agree with the statement, 4 for those who agree and so on down to 1 for those who strongly disagree. For the analysis of this article, options agree (4) and strongly agree (5) are combined, answers that fall in this section shall be considered as a strong positive attitude (SP); disagreement responses (2) and strongly disagree (1) are also combined; answers in this section are considered strongly negative (SN), see Table 2 . The level of attitude is considered SN or SP if the answers (combined) reach a percentage equal or higher than $80 \%$, if the answers reach a percentage below this value, they are considered neutral $(\mathrm{N})$.

Table 2. Attitude scale

\begin{tabular}{|c|c|}
\hline Attitude & Scale \\
\hline Strong positive (SP) & 5 and 4 \\
\hline Neutral & 3 \\
\hline Strong negative (SN) & 2 and 1 \\
\hline
\end{tabular}

On the other hand, at the end of the course, we applied a post-test, which focused to determine if students accept or reject GR. MAQ was modified in order to obtain a 
questionnaire related to GR attitude (GRAQ), some items are:

\section{Using GR in algebra is fun}

$\begin{array}{llllll}\begin{array}{l}\text { a. } \\ \text { agree }\end{array} & \text { strongly } & \text { b. agree } & \text { c. undecide } & \text { d. disagree } & \begin{array}{l}\text { e. strongly } \\ \text { disagree }\end{array}\end{array}$

\section{I understand better algebra when I work in groups and use GR}

$\begin{array}{llllll}\begin{array}{l}\text { a. strongly } \\ \text { agree }\end{array} & \text { b. agree } & \text { c. undecide } & \text { d. disagree } & \text { e. strongly } \\ \text { disagree }\end{array}$

The questionnaire has two sections like MAQ: a) individual, b) collaborative. Now, the analysis for each questionnaire is shown.

\subsection{Section I (Attitude in General)}

Table 3 shows results from MAQ and GRAQ (pretest in both cases). Let us begin analyzing MAQ results. Data indicate that $31 \%(\mathbf{N})$ of students get nervous while they resolve an exam (item 7), just $40 \%$ indicate the opposite. $76 \%(\mathrm{~N})$ of population consider math taught in school is useful and 97\% (SP) indicate that math will be helpful in their later life (item 8 and 12). In the other side, $93 \%$ (SP) think they are meticulous when they resolve a problem (item 16). With these data, we can suppose that these students have good attitude toward math, so increasing that attitude at the end of the course represented a challenge for the research.

Now, let us analyze posttest (GRAQ) results for section I. We have to remember section I focused on general attitude. So, $81 \%$ (SP) consider GR was useful in factoring topics and 93\% (SP) indicate that GR was useful to understand algebra topics (item 8 and 9); 82\% would recommend this math tool, 75\% reject that GR is a useless tool. These results indicate that students show a strong positive attitude toward the new methodology and it can be said that our students reached a high-level attitude in math and in GR. We have to remarked that those items (pretest and posttest) are very similar, pretest focused on general math and posttest on GR.

Table 3. Results for Section I

\begin{tabular}{|l|r|r|r|r|r|r|r|r|}
\hline \multicolumn{5}{|c|}{ Pre-test \% } & \multicolumn{4}{c|}{ Post-test \% } \\
\hline item & $\mathbf{7}$ & $\mathbf{8}$ & $\mathbf{1 2}$ & $\mathbf{1 6}$ & $\mathbf{8}$ & $\mathbf{9}$ & $\mathbf{1 2}$ & $\mathbf{1 3}$ \\
\hline SP & 44.82 & 20.68 & 93.1 & 96.55 & 81.48 & 92.59 & 81.48 & 12.81 \\
\hline N & 24.13 & 3.44 & 0 & 0 & 7.4 & 3.7 & 11.11 & 13.81 \\
\hline SN & 31.03 & 75.86 & 6.89 & 3.44 & 11.11 & 3.7 & 7.4 & 75.37 \\
\hline
\end{tabular}

\subsection{Section II (Attitude on Group Work)}

Now, student's attitude in teamwork (MAQ: pretest) will be analyzed. Item 18, indicates that students $(31 \%)$ do not like to work in board. However, students show (item 19) neutral attitude to work in teams and to support their classmate (69\%). They are impatient to start to 
solve any problem, $66 \%$ starts to work without check the strategy with their mates. Moreover, $71 \%$ supposes they have good skill in math (see Table 4 ). In general, there are neutral attitude toward math teamwork.

On the other hand, results of GRAQ (posttest) are show in Table 4 and indicate that teamwork represents a better trend to strong positive (81\%) in order to support their mates. The trends to help others mates increase to $82 \%$ (SP), this mean it was able to encourage them to be solidary among them. In addition, confidence in math reached $82 \%(\mathbf{S P})$, so the methodology motivates our students to be interesting in mathematics and increases good attitude. These results indicate clearly that motivation in teaching algebra is a very important factor in order to produce a good academic performance on students. Traditional teaching method do not provoke that goal and it is probably a big obstacle for learning algebra topics, particularly in factorization. In fact, we consider that a low motivation in class could provoke a high rate in failure. We have to remark that those items (pretest and posttest) are very similar, pretest focused on general math and posttest on GR.

Table 4. Results for section II

\begin{tabular}{|l|r|r|r|r|r|r|r|r|r|r|}
\hline \multicolumn{5}{|c|}{ Pre-test \% } & \multicolumn{5}{|c|}{ Post-test \% } \\
\hline Item & $\mathbf{1 8}$ & $\mathbf{1 9}$ & $\mathbf{2 0}$ & $\mathbf{2 2}$ & $\mathbf{2 4}$ & $\mathbf{1 6}$ & $\mathbf{1 7}$ & $\mathbf{1 8}$ & $\mathbf{2 0}$ & $\mathbf{2 2}$ \\
\hline SP & 31.03 & 65.51 & 68.96 & 65.51 & 71.51 & 40.74 & 81.77 & 81.48 & 55.55 & 81.77 \\
\hline N & 37.93 & 24.13 & 17.24 & 20.68 & 20.13 & 40.74 & 7.4 & 11.11 & 29.62 & 19.22 \\
\hline SN & 31.03 & 10.34 & 13.79 & 13.79 & 8.34 & 18.51 & 10.81 & 7.4 & 14.81 & 0 \\
\hline
\end{tabular}

These results indicate that students reach a high level in math attitude, upper than traditional teaching method. It can be tell that students prefer GR rather than traditional rules for factoring polynomials because GR allows them to learn the rules easier, they can see parts of polynomial in a geometry figure and do not have to think in abstract rules but geometry rules.

\section{Conclusion}

Generic rectangle is a visual tool that let students factoring quadratic following simple steps, which facilitate the learning in that topic; no matter which case they face because Algorithm 1.1 is useful for all cases in factorization. Traditional teaching method involves a special rule for each case and students commonly tend to forget it. By implementing GR in "introduction to engineering", a better academic behavior, good attitude during classes and willingness to learn the new tool was found.

Comparing 2014 and 2015 results, it was found that in 2015 after instruction, 84\% of our students resolve correctly the final exam using GR. However, in 2014 students who used traditional method obtained unfavorable results (just 28\% obtained good results in the final exam). In both years, the exams applied were similar, same topics during the same time. Hypothesis test indicates there are meaningful differences between GR and traditional 
method in order to learn factoring quadratics, it means, using GR, students learn better this topics than using traditional method. Students can factoring more efficiently and with more confidence, because rate of failure lowered from $60 \%$ to $15 \%$. This was one of our aim. In the other hand, GRAQ's results have showed that GR increase strong positive attitudes, in comparison with traditional method. Teamwork improved quite a lot because $80 \%$ accepted that teamwork is very important, as well as solidarity (82\%) with their mates in order to solve some problems, among others. Attitude after instruction with GR increased to strong positive level, and students finished the course motivated (this was the second aim).

We have to remark that it is very important to give the instructions using contextualized problems (in this case, focused on petroleum engineering). With these kind of problems, students were more interested in all topics taught because they could see how useful it will be for them in the next subjects and they learned a bit about new concepts in petroleum, such as drilling costs, pipe pressures, specific gravity, among others.

The results point out that if we want to have students with high academic performances we have to focus on encourage them to unleash their potential and let them tray with news methodologies. So, it can be said that generic rectangle promote meaningful learning in factoring quadratics and have a strong positive attitude toward math.

\section{References}

Álvarez, Y., \& Ruiz Soler, M. (2010). Engineering students'attitude toward math in universities of Venezuela. Revista de Pedagogía, 225-249.

Arriaga, A., \& Benítez, M. (2011). Mathematics. Introduction to competencies. Pearson Educación, Segunda edición. México.

Baldor, A. (2012). Algebra. Patria. Quinta edición, México.

Boehrer, J. y M. Linsky (1990). Teaching with Cases: Learning to Question, en Svinicki, M.D. (ed.), The Changing Face of College Teaching. New Directions for Teaching and Learning, no. 42. San Francisco: Jossey-Bass.

Gatley, W. (1991). Algebra tiles. Program Service Vancouver School Board Vancouver, BC.

Hedden, J. W. (1989). Bridging the gap between the concret and the abstract. Arithmetic's teachers, $33,14-17$.

Ibáñez, P., \& García, G. (2010). Mathematics I. Aritmhetics y algebra. Cengage Learning, $1 \mathrm{fh}$ edition. México.

Kurumeh, M. S., Chiawa, M. A., \& Ibrahim, M. O. (2010). Dienes multibases blocks approach: an effective strategy for improving interest in number bases among secondary school students in mathematics. Research journals of mathematics and statistics, 2, 101-104.

Kline, M. (1973). Why Johnny can't add: the failure of the new math. St. Martin's Press.

Larbi, E. (2011). The effect of algebra tiles on student's performance in algebra at the junior high school. Master thesis, Universidad of Cape Coast, Cape Coast. 


\section{Macrothink}

International Research in Education

ISSN 2327-5499

2017, Vol. 5, No. 1

Levin, R., \& Rubin, D. (2004). Statistics for administration and economy. Pearson Educación. Séptima Edición. México.

Morales, I., \& Sepúlveda, A. (2009). Proposal for teaching factoring in algebra course. Memorias XIV Encuentro de Profesores de Matemáticas.

Rojas, H. (2009). Teaching algebra from methodological approach on solving problems teaching. Universidad Tangamanga Revista Electrónica Ciencias de la Educación. 4, Art. 11.

Salazar, L., Vega, F., \& Bahena, H. (2015, May 05). An option to learn arithmetic and algebra. Consejo Nacional de Educación para la vida y el trabajo. Retrieved from http://bibliotecadigital.conevyt.org.mx/colecciones/documentos/somece/93.pdf

Schoenfeld, A. (2015, Mar 25). Reflections on Problem Solving Theory and Practice. Time, 10 (1\&2), 9. Retrieved from http://www.math.umt.edu/tmme/vol10no1and2/1-Schoenfeld _pp9_34.pdf

Sandoval, M., García, M., \& Velázquez, G. (2014). Introduction to algebra, geometry and trigonometry. EUMED, España.

Santos, D., Ursini, S., Ramírez, M. P., \& Sánchez, G. (2006). Mathematics achievement: Sex differences vs gender differences. International groups for the psychology of mathematics education, 5, 41-48,

Sharp, J. (1995). Results of using algebra tiles as meaningful representation of algebra concepts. Annual meeting of the Mid western education research association, Chicago.

Sowell, E. J. (1989). Effect of manipulative materials in mathematics instruction. Journals for research in mathematics education, 20, 498-505

Tobón, S. (2010). Instruction base on competency: complex thinking, curricular design and didactic. Colombia: Ecoe.

Thornton, G. (1995). Algebra tiles and learning style (Master thesis). Simon Fraser University.

\section{Appendix}

Generic rectangle attitudinal questionnaire

Answer the following questions as accurately as possible. Only circle the response that is closest to the way you feel. Respond to all questions.

1. I liked GR tool
a) Strongly agree
b) Agree
c) Undecided
d) Disagree
e) Strongly disagree

2. I found using GR is very dull 

a) Strongly agree
b) Agree
c) Undecided
d)Disagree
e) Strongly disagree

3. I enjoyed the polynomial factoring with GR
a) Strongly agree
b) Agre
c) Undecided
d)Disagre
e)
Strongly $\mathrm{e}$
e
disagree

4. Generic rectangle was very funny
a) Strongly agree
b) Agree
c) Undecided
d)Disagree
e) Strongly disagree

5. The GR is one of my favorite topics in math
a) Strongly agree
b) Agree
c) Undecided
d)Disagree
e) Strongly disagree

6. The GR help me to understand polynomials factoring a lot better than I would have done without it.
a) Strongly agree
b) Agree
c) Undecided
d)Disagree
e) Strongly disagree

7. Hands on materials such as GR make understanding math a lot easier
a) Strongly agree
b) Agree
c) Undecided
d)Disagree
e)
Strongly
disagree

8. If you were ask for your teacher whether or not you would encourage the use of GR when learning factoring quadratics, would you:
a) Strongly
b) Encourage
c) Indifferen
d)
e)
Strongly encourage
$\mathrm{t}$
Discourage
discourage

9. Did you find using GR very time consuming and not very helpful to your understanding of factoring quadratics?
a) Strongly agree
b) Agree
c) Undecided
d)Disagree
e) Strongly disagree

10. I preferred working GR on my own rather than in groups during math class
a) Strongly agree
b) Agree
c) Undecided
d)Disagree
e)
Strongly

11. I understood GR topics better when we work in groups
a) Strongly agree
b) Agree
c) Undecided
d)Disagree
e) Strongly disagree

12. I enjoyed doing GR questions on the board in front of the whole class
a) Strongly agree
b) Agree
c) Undecided
d)Disagree
e)
Strongly

13. I enjoy working in groups to study and work on GR
a) Strongly agree
b) Agree
c) Undecided
d)Disagree e)
disagree
Strongly 
14. I enjoy helping other when we were working with GR
a) Strongly agree
b) Agree
c) Undecided
d)Disagree
e) Strongly disagree

15. When given a problem, I like to start immediately rather than having to discuss it with others in my group
a) Strongly agree
b) Agree
c) Undecided
d)Disagree
e) Strongly disagree

16. When given a problem, I waited until others has started to make sure that was doing it right
a) Strongly agree
b) Agree
c) Undecided
d)Disagree
e)
Strongly
disagree

\section{Copyright Disclaimer}

Copyright reserved by the authors.

This article is an open-access article distributed under the terms and conditions of the Creative Commons Attribution license (http://creativecommons.org/licenses/by/3.0/). 